\title{
The environment influences whether high-fat foods are associated with palatable or with unhealthy
}

Citation for published version (APA):

Roefs, A. J., Quaedackers, L. X., Werrij, M. Q., Wolters, G., Havermans, R. C., Nederkoorn, C., van Breukelen, G. J. P., \& Jansen, A. T. M. (2006). The environment influences whether high-fat foods are associated with palatable or with unhealthy. Behaviour Research and Therapy, 44(5), 715-736. https://doi.org/10.1016/j.brat.2005.05.007

Document status and date:

Published: 01/01/2006

DOI:

10.1016/j.brat.2005.05.007

Document Version:

Publisher's PDF, also known as Version of record

Document license:

Taverne

Please check the document version of this publication:

- A submitted manuscript is the version of the article upon submission and before peer-review. There can be important differences between the submitted version and the official published version of record.

People interested in the research are advised to contact the author for the final version of the publication, or visit the DOI to the publisher's website.

- The final author version and the galley proof are versions of the publication after peer review.

- The final published version features the final layout of the paper including the volume, issue and page numbers.

Link to publication

\footnotetext{
General rights Owners
rights.

- You may freely distribute the URL identifying the publication in the public portal. please follow below link for the End User Agreement:

www.umlib.nl/taverne-license

Take down policy

If you believe that this document breaches copyright please contact us at:

repository@maastrichtuniversity.nl

providing details and we will investigate your claim.
}

Copyright and moral rights for the publications made accessible in the public portal are retained by the authors and/or other copyright owners and it is a condition of accessing publications that users recognise and abide by the legal requirements associated with these

- Users may download and print one copy of any publication from the public portal for the purpose of private study or research.

- You may not further distribute the material or use it for any profit-making activity or commercial gain

If the publication is distributed under the terms of Article $25 \mathrm{fa}$ of the Dutch Copyright Act, indicated by the "Taverne" license above, 


\title{
The environment influences whether high-fat foods are associated with palatable or with unhealthy
}

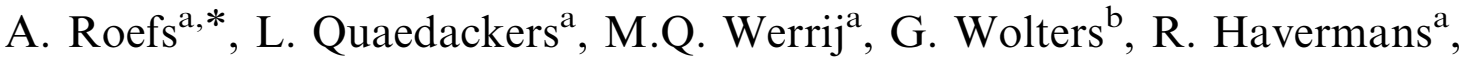 \\ C. Nederkoorn ${ }^{a}$, G. van Breukelen ${ }^{\mathrm{a}}$, A. Jansen ${ }^{\mathrm{a}}$ \\ ${ }^{a}$ Maastricht University, P.O. Box 616, 6200 MD Maastricht, The Netherlands \\ ${ }^{\mathrm{b}}$ Atrium Hospital, Brunssum, The Netherlands
}

Received 16 July 2004; received in revised form 1 April 2005; accepted 16 May 2005

\begin{abstract}
This study investigated whether relatively automatic evaluations of food differ between situations and between obese people and lean controls. These evaluations were assessed in the affective priming paradigm (APP) - a response latency based measure for associations. In Experiment 1, we either focused participants (33 obese and 26 lean controls) on the palatability (restaurant condition) or on the healthiness (health condition) of food, prior to the APP. Independent of weight-status, relatively automatic evaluations of food were based on palatability in the restaurant condition, and on health in the health condition. So, the current focus of attention can shape the way foods are evaluated relatively automatically. In Experiment 2, craving was induced in participants (27 obese and 29 lean controls). Unexpectedly, the craving induction did not achieve its goal of focusing on the palatability of food in general, but just for low-fat foods, possibly because of the health-emphasizing environment - a hospital. Interestingly, obese people showed a stronger palatability priming effect with increasing levels of initial craving. For normal weight controls the effect was in the same direction, but missed significance. In our environment, palatability of food may be too salient, and health may not be salient enough, influencing automatic food-evaluations.
\end{abstract}

(C) 2005 Elsevier Ltd. All rights reserved.

Keywords: Eating attitudes; Obesity; Affective priming paradigm; Automatic evaluation

\footnotetext{
*Corresponding author. Tel.: + 31433882191 ; fax: + 31433884196.

E-mail addresses: roefs@psychology.unimaas.nl (A. Roefs), L.Quaedackers@student.unimaas.nl (L. Quaedackers), M.Werrij@psychology.unimaas.nl (M.Q. Werrij), psychologen.gulpen@freeler.nl (G. Wolters),

R.Havermans@psychology.unimaas.nl (R. Havermans), C.Nederkoorn@psychology.unimaas.nl (C. Nederkoorn), Gerard.vBreukelen@STAT.unimaas.nl (G. van Breukelen), A.Jansen@psychology.unimaas.nl (A. Jansen).
} 


\section{Introduction}

The intake of high-fat foods seems an important factor contributing to the global obesity epidemic (e.g., Lissner \& Heitmann, 1995). This heightened intake of high-fat foods in obese people may be caused by an increased preference for this type of food (Rissanen et al., 2002). An approach to assess these food preferences is to employ so-called indirect measures. Recently, there has been an enormous increase in the application of indirect measures, such as the affective priming paradigm (APP) (Fazio, Sanbonmatsu, Powell, \& Kardes, 1986) and the Implicit Association Test (IAT; Greenwald, McGhee, \& Schwartz, 1998), in clinical psychology (e.g., de Jong, Pasman, Kindt, \& van den Hout, 2001; Roefs \& Jansen, 2002; Teachman, Gregg, \& Woody, 2001).

In the two experiments reported in this article, one of these indirect measures was used: the APP. In this paradigm, two word-stimuli are presented in quick succession, a prime followed by a target. The participant does not need to respond to the prime, which is simply displayed and replaced by the target. The participant only needs to decide as quickly as possible whether the target word is positive or negative. The dependent variables are the response latency in response to the target and the percentage of errors. The focus of the paradigm is on the extent to which the presentation of the prime influences the response to the target. Typically (e.g., Bargh, Chaiken, Govender, \& Pratto, 1992; Fazio et al., 1986; Hermans, De Houwer, \& Eelen, 1994, 2001), affectively congruent prime-target pairs (e.g., "love"-"happy") lead to shorter response latencies to the target word than do affectively incongruent prime-target pairs (e.g., "love"-_awful"). The critical idea is that the pattern of response latencies as a function of affect match between prime and target indicates how people evaluate the prime on a fairly automatic level. Applied to the palatability of food, if people respond faster on congruent trials ('palatable - positive' and 'unpalatable - negative') than on incongruent trials ('palatable - negative' and 'unpalatablepositive'), it can be inferred that they like palatable foods more than unpalatable foods.

These indirect measures are designed to tap automatic associations or attitudes. One of the main reasons for indirect measures' popularity is the assumption that these automatic processes are inflexible - stable across situations - and cannot be influenced by someone's goals or intentions. This assumption has contributed to the idea that attitudes or evaluations assessed by these indirect measures may represent someone's true attitude or evaluation (Blair, 2002). Fazio, Jackson, Dunton, and Williams (1995) even called the affective priming paradigm a "bona fide pipeline" for attitude or evaluation measurement. This certainly would be an interesting way of assessing food preferences.

However, Banaji (2001) pointed out that both indirect and direct measures (e.g., self-reports) can be valid indicators of attitudes or associations, "each of a different form of the same attitude object and within the same mind (p. 136)." Also Fazio and Olson (2003) now share this point of view, and according to their MODE model (Fazio \& Towles-Schwen, 1999), which type of measure (indirect vs. direct) is predictive of behavior depends on someone's motivation and opportunity to engage in more controlled processing. So, though there may not be such thing as a "real attitude", the study of automatic evaluations is still interesting in that it can be very informative to assess what someone's relatively spontaneous associations are, because they guide behavior when there is no opportunity or motivation for more controlled processing. This also holds true for research into food preferences of obese people. When these food preferences are 
assessed in a paradigm in which not much time for controlled processing is left, participants give their "first" impression of that food. This early association is plausibly based on taste, because taste is considered the most important characteristic of food (Eertmans, Baeyens, \& Van den Bergh, 2001), and thus likely to be the basis of categorization (Smith, Fazio, \& Cejka, 1996). If it was shown that obese people are characterized by a stronger positive association with (high-fat) palatable food, it would follow that they would always have to suppress this initial response to avoid eating too much (high-fat) food.

It is important to note, following Fazio and Olson (2003), that an evaluation or attitude assessed by an indirect measure is not necessarily an unconscious one. Participants may not be aware of what the task is assessing, because the measurement is indirect, but they may very well be aware of their attitude or evaluation. Because the term 'implicit' seems to carry the notion of 'unconscious', we follow Fazio \& Olson (2003; see e.g., MacLeod, 1989) in using the terms 'indirect' and 'direct', instead of 'implicit' and 'explicit'. Responses are assumed to be relatively automatic in this kind of task, because stimuli are presented in quick succession and participants are urged to respond as quickly as possible, leaving insufficient time for controlled processing. In other words, people may not be able to control the impact of their attitude on performance on the indirect task, and may not have that intention (Blair, 2002). Thus, the term automatic is not equivalent to the term unconscious, but rather means that indirect measures leave insufficient time for participants to strategically control their response.

Prior research in our laboratory used both the IAT (Greenwald et al., 1998) and the APP (Fazio et al., 1986) to study relatively automatic associations with food (see also Lamote, Hermans, Baeyens, \& Eelen, 2004) in various groups of participants, such as obese people (Roefs \& Jansen, 2002; Roefs, Stapert, et al., 2005), restrained eaters (i.e., people who intend to control their food intake, but regularly fail and indulge in the foods they crave; Roefs, Herman, MacLeod, Smulders, \& Jansen, 2005), and anorexia nervosa patients (Roefs, Stapert, et al., 2005). Based on prior research that suggest that obese people have a preference for high-fat foods (e.g., Drewnowski, Kurth, Holden Wiltse, \& Saari, 1992; Rissanen et al., 2002) and consume more of these foods (Lissner \& Heitmann, 1995), we hypothesized that they would have stronger positive associations with (high-fat) palatable foods.

However, both studies with obese participants in our laboratory suggested that obese people and normal weight people alike have more negative associations with high-fat (palatable) foods than with low-fat (palatable) foods. Explanations for these relatively negative associations may be found in (subtle) context effects. It is common knowledge that attitudes assessed by direct measures (e.g., questionnaires) can be influenced by context (Schwarz, 1999), but as Blair (2002) reviews, attitudes or evaluations assessed by indirect measures can also be influenced by the current context and the focus of attention. This apparent malleability of automatic attitudes or evaluations has important consequences. It certainly suggests that there might not be one uniform and stable automatic association with a certain attitude object that influences responding when there is no motivation or opportunity to engage in more controlled processing. So, these automatic associations seem neither to reflect a true attitude nor do they seem to be stable across situations. A rather large body of research now suggests that automatic associations are more flexible and situation-specific than was assumed before (Blair, 2002). So, it may be more accurate to view attitudes or evaluations not as static entities, but as influenced by the immediate situation and current focus of attention (Mitchell, Nosek, \& Banaji, 2003). 
To return to the role of context and focus of attention in our food studies, a first study in our laboratory comparing obese and normal weight controls (Roefs \& Jansen, 2002) used the IAT (Greenwald et al., 1998). In this study, a relatively negative association with high-fat foods was found, which was most pronounced for the obese participants. In an IAT, participants are asked to categorize concept and attribute stimuli into predefined categories (in our study: 'high-fat' vs. 'low-fat' and 'positive' vs. 'negative'). Importantly, IAT effects have been shown to be strongly influenced by these category labels (De Houwer, 2001, 2003). So, the IAT at least partly reflects an attitude toward the category (e.g., 'high-fat foods'), instead of toward individual exemplars (e.g., 'chocolate'). It is perhaps unsurprising that people dislike the fact that chocolate is high-fat, even though they love the taste of chocolate. Similarly, research by Mitchell et al. (2003) showed that the basis of categorization - focus of attention - influences the automatic attitude dramatically. For example, their results showed that participants had more positive associations with admired black athletes than with disliked white politicians when participants had to categorize stimuli by occupation, whereas participants had more negative associations with admired black athletes than with disliked white politicians when participants had to categorize stimuli by race. This suggests that people do not have one simple association with an attitude object, and that the association is dependent on the current focus of attention (occupation vs. race). In sum, in the study by Roefs and Jansen (2002) the fat content of the food - which was the basis of categorization - was a salient characteristic, which might have led to the negative associations with high-fat foods.

In a related study (Roefs, Stapert, et al., 2005), we used the affective priming paradigm (Fazio et al., 1986), in which participants were not required to sort stimuli into predefined categories (e.g., high-fat vs. low-fat). In other words, participants' responses were not steered in a certain direction in this paradigm, but were activated upon presentation of the prime, and influenced responding to the target. Notably, also in this study we found evidence for more negative associations with high-fat palatable foods than with low-fat palatable foods for both obese and normal weight controls. This finding might be explained by a more subtle context effect, namely the environment in which this study took place: a local hospital. A hospital is an environment in which 'health' is obviously salient. As Lowery, Hardin, and Sinclair (2001) showed, even a rather subtle manipulation of context (cf. hospital environment) can considerably influence automatic evaluations or attitudes. In their studies on racial attitudes, they found less automatic prejudice when a black experimenter conducted the study than when a white experimenter conducted the study. As discussed by Lowery et al., this finding is remarkable, because of the common assumption that prejudice is automatically activated when a member of a prejudiced group is present (Bargh, 1999).

In conclusion, an evaluation of food may not be the same in every situation and might depend on the current focus of attention. The palatability of a food is the most important characteristic of a food for most people (Eertmans, et al., 2001). However the healthiness of a food certainly matters as well, maybe especially in our society, in which a slim figure is considered very important (Puhl \& Brownell, 2003; Teachman \& Brownell, 2001). So, foods are actually multiply categorizable items (Smith et al., 1996). A food can be categorized as palatable vs. unpalatable, or can be categorized as healthy vs. unhealthy (i.e. fattening). In both of our prior studies with obese people, healthiness of foods wasunintentionally - made salient, either by the basis of categorization (high-fat vs. low-fat) or by the environment (hospital). In the current studies we will-intentionally - manipulate the salience of taste and health aspects of food, and study how this affects priming effects. Moreover, in both experiments the influence of weight status (obese vs. lean control) on the priming effect will be studied. 


\section{Experiment 1}

In Experiment 1 we attempted to manipulate participants' focus of attention, by either highlighting the palatability of food or highlighting the health aspects of food. In the first condition (restaurant condition) participants were asked to imagine they were a restaurant owner about to prepare a special gourmet dinner. In the second condition (health), participants were given information about healthy eating patterns, and a short assignment. The manipulation was a between-subjects factor, and participants were randomly assigned to one of these conditions. These manipulations took place just before participants started the affective priming task, the indirect measure for assessing evaluations of food. We hypothesized that in the first condition (restaurant condition), a relatively automatic evaluation of food would be based on taste aspects, whereas we expected it to be based on health aspects in the second condition (health). More specifically, in the restaurant condition we expected participants to display a liking of palatable foods over unpalatable foods. Moreover, we expected a liking of high-fat foods over low-fat foods because high-fat foods are typically craved more frequently than low-fat foods (Hill \& HeatonBrown, 1994; Weingarten \& Elston, 1991), and the items in the restaurant task were high-fat palatable foods. In the health condition, we expected participants to display a preference for lowfat foods over high-fat foods. A priori we did not have an expectation about the effect of palatability, because we did not know which type of food (palatable vs. unpalatable) would be considered as healthier. Note that the healthiness of the different types of food was checked in a direct health rating task (see Method).

Moreover, we were interested in the effects of weight-status (obese vs. lean control) on the food priming effect. Based on prior research that suggests that obese people are more sensitive to the palatability of food (for a review see: Pliner, Herman, \& Polivy, 1990) and that they have a specific preference for high-fat foods (e.g., Drewnowski et al., 1992; Gerding \& Weinstein, 1992; Rissanen et al., 2002), we hypothesized that the obese participants would show a specific preference for high-fat palatable foods.

\section{Method}

\section{Participants}

Participants were 33 obese women $\left(\mathrm{BMI}^{1}>30\right)$ and 26 female lean unrestrained eaters. Restraint-status was determined by the Restraint Scale (Herman \& Polivy, 1980). A participant qualified as an unrestrained eater when she scored 14 or below on this scale. Participants were recruited by advertisements in a Dutch women's magazine and in local newspapers. See Table 1 for participant characteristics.

Several additional participants - not included in the groups described above - were tested, but were excluded from analyses based on beforehand defined exclusion criteria. Three participants (1 obese and 2 lean controls) were excluded because of a high percentage $(>M+3 S D)$ of errors or responses that were either too fast or too slow, on the affective priming task. Eleven participants were excluded because they did not meet the criteria for one of the two groups (BMI and Restraint Scale total score).

\footnotetext{
${ }^{1} \mathrm{BMI}=$ Body Mass Index $=$ weight $/$ height $^{2}$.
} 
Table 1

Experiment 1

\begin{tabular}{lllllr}
\hline & Obese $(n=33)$ & Control $(n=26)$ & $t$ & df & $p$ \\
\hline Age & $41.7(6.9)$ & $41.8(8.1)$ & 0.05 & 57 & 0.96 \\
BMI & $38.1(4.7)$ & $22.2(1.7)$ & & & \\
& $\left(R^{\mathrm{a}}: 30.2-46.8\right)$ & $(R: 19.5-24.9)$ & 18.0 & $41.7^{\mathrm{b}}$ & $<0.001$ \\
Restraint scale & $19.3(5.3)$ & $8.5(2.3)$ & 10.4 & $44.05^{\mathrm{b}, \mathrm{c}}$ & $<0.001$ \\
\hline
\end{tabular}

Participant characteristics, with $S D$ in parentheses.

${ }^{\mathrm{a}} R=$ Range.

${ }^{\mathrm{b}}$ Equality of variances could not be assumed.

${ }^{\mathrm{c}}$ One of the obese participants did not fill out the Restraint scale.

Stimulus selection and timing of trials in the priming task

Primes. Six high-fat palatable foods (e.g., chocolate), six low-fat palatable foods (e.g., strawberries), six high-fat unpalatable foods (e.g., bacon), and six low-fat unpalatable foods (e.g., radish) served as primes (see Appendix). The four groups of primes did not differ significantly in word length, $F(3,20)<1$. Palatability was determined on the basis of a pilot study, in which it was tested which foods are generally liked and disliked by female university students $(n=64)$.

In this pilot study, participants were given two separate sheets of paper. On one sheet, a list of 28 high-fat foods was printed; on the other sheet, a list of 33 low-fat foods was printed. These foods were mainly selected by using a food composition table (Nevo Tabel, Nederlands voedingsstoffenbestand (NEVO), 1993). High-fat and low-fat foods were on separate lists because participants might otherwise have been "tempted" to give low-fat foods a better rank, which may be seen as socially desirable. They were asked to choose from each list the eight foods that they liked most, and the 8 foods that they disliked most. Then they were asked to rank the eight foods that they (dis)liked the most from each list from 1 ((dis)like the most) to 8 ((dis)like the least). Stimulus selection for the current experiment was based on the mean ranking of a food, weighted by the number of participants who put that food in their selection of (dis)liked foods. In this way, we selected 6 high-fat liked, 6 high-fat disliked, 6 low-fat liked, and 6 low-fat disliked foods (see Appendix).

Targets. Twenty-four general positive (e.g., "gift”) and 24 general negative (e.g., "pain") words served as targets (see Appendix), and were selected according to word norms by Hermans and De Houwer (1994), who had participants rate a large number of words on 7-point scales (1-7) for pleasantness ("very negative-very positive") and familiarity ("familiar-unfamiliar"). The two groups of stimuli obviously differed significantly in pleasantness (negative: $M=2.0, S D=0.31$ vs. positive: $M=6.0, S D=0.29), t(46)=46.25, p<0.001$. There were no significant differences between the two groups of stimuli in affective extremity (negative: $M=2.0, S D=0.31$ vs. positive: $M=2.0, S D=0.29$ ), $t(46)<1$, or word length (negative: $M=6.2, S D=2.02$ vs. positive: $M=6.79, S D=2.13), t(46)<1$. However, a small significant difference in familiarity ratings was found (negative: $M=4.8, S D=0.45$ vs. positive: $M=5.1, S D=0.48$ ), $t(46)=2.38$, $p<0.05$. Primes and targets were presented in black lower-case letters (6 mm high) against a light background on a computer monitor (see Appendix). 
Randomization of stimuli. Each participant was given 144 trials, split up into 3 blocks of 48 each. Each food-stimulus (prime) was paired once with a positive and once with a negative target in each block. All primes had been presented once (with either a positive or a negative target) before any prime was presented for the second time in each block. For each participant, and for each of the three blocks, it was determined randomly which half of each of the types of primes (high-fat palatable, high-fat unpalatable, low-fat palatable, low-fat unpalatable) would be paired first with a positive/negative target. Primes and targets were both randomly selected (unique for each participant) from their respective sets without replacement.

Trial timing. The timing of trials was modeled after the procedure of Hermans et al. (2001). All stimuli were presented in the center of the monitor. Each trial started with a fixation cross $(700 \mathrm{~ms})$. Then the prime was presented for $150 \mathrm{~ms}$. After a $150 \mathrm{~ms}$ stimulus onset asynchrony (SOA) - the time that elapses between the onset of the prime and the onset of the target - the target was presented on the monitor. The target remained on the monitor until a response was given or for $2500 \mathrm{~ms}$ if no response was given. If an error was made or a response was either too slow or too fast, or if no response at all was given, a warning appeared on the screen for $300 \mathrm{~ms}$. The inter-trial interval was $2500 \mathrm{~ms}$.

\section{Materials}

Manipulations. The 'restaurant task' was intended to focus participants on the (un) palatability of foods. In this task participants were asked to imagine that they were a chef in a fancy restaurant, and that they had to prepare a special dinner for a wedding. They were presented with 14 sets of 2 menu-items and they were asked to indicate each time which menu-item they liked best. All menu-items were high-fat palatable foods.

The 'health task' was intended to focus participants on the health aspects of food. Participants were given an information sheet about healthy eating habits. This information emphasized that high-fat foods are fattening and unhealthy when consumed too much. Then they were presented with 14 sets of 2 menu-items. Each set consisted of a clearly healthy and a clearly unhealthy (high-fat) menu-item. Participants were asked to indicate which menu-item they thought was the healthiest.

Direct rating task of foods. Whereas palatability was based on a pilot study, health ratings for the four types of food were asked in a brief questionnaire. The 24 foods that were used as primes were presented in a random order (identical for all participants) on a paper-and-pencil rating task. Participants were asked to rate the foods on health (7-point scale: 1: very unhealthy-7: very healthy).

Restraint Scale. The Restraint Scale measures "the extent to which participants show evidence of dieting and concern about their weight" (Herman \& Polivy, 1980, p. 212). The minimum score on this scale is 0 and the maximum score is 35 .

\section{Procedure}

Participants were tested in session-groups of up to 13 people, in research cubicles. All testing took place between 1.30 and $2.30 \mathrm{pm}$. The experimenter was present during the entire procedure. First, they were given instructions on how to perform the priming task. They were instructed to read each word that appeared first on the monitor silently, and then to decide whether each second word was positive or negative, pressing the corresponding key on the key box (key 
assignment was counterbalanced across participants). They were told to respond as quickly as possible but to avoid making too many mistakes. Participants were then presented with 16 practice trials using stimulus materials different from those on the experimental trials. Similar to Zack, Toneatto, and MacLeod (1989), they were given a free recall test for the primes immediately after the practice trials, writing down as many words as they could remember that appeared as a first word (prime) on the computer task that they had just performed. This task was included to ensure that participants paid attention to both primes and targets by raising the possibility that participants might be asked to perform such a free recall task later in the procedure. After this memory test, 16 of the obese participants and 14 of the lean control participants received the 'restaurant task'. Seventeen of the obese and 12 of the lean control participants received the 'health task' (tasks were randomly assigned to participants within each session group).

Participants were given a brief repetition of the instruction for the priming task, and were then ready to begin the actual priming task, which was made up of three blocks, with short breaks in between. After the final block of the priming task, the participants were again given a free recall test for the primes. Administration of the Restraint Scale (Herman \& Polivy, 1980), and the measurement of weight and height took place after participation in another unrelated experiment on the same day.

\section{Apparatus}

The experiment was carried out on Dell Optiplex GX260 computers with Pentium IV processors, connected to Dell M992 monitors. Key responses were registered by external response devices with better than $1 \mathrm{~ms}$ accuracy. The software controlling the experiment was programmed in ERTS (Experimental Run Time System, Beringer, 1996).

\section{Design and analysis procedure affective priming paradigm}

Data were analyzed using a 2 (target affect: positive vs. negative) $\times 2$ (fat-content prime: highfat vs. low-fat) $\times 2$ (palatability of prime: palatable vs. unpalatable) $\times 2$ (group: obese vs. control) $\times 2$ (manipulation: restaurant vs. health) analysis of variance (ANOVA). The factors target affect, fat-content prime, and palatability of prime were within-subjects factors, whereas group and manipulation were between-subjects factors. An interaction between prime and target indicates that there is a priming effect (i.e., that the presentation of the prime influences the speed and accuracy of responding to the target). Note that there can be an interaction between prime palatability and target affect, suggesting an automatic evaluation of taste, and an interaction between prime fat content and target affect, suggesting an automatic evaluation of fat-content. Partial eta squared $\left(\eta^{2}\right)$ is reported as a measure of effect size for all analyses.

\section{Results and discussion}

\section{Direct rating task food}

First, the health ratings for the four types of food primes were analyzed to check how these four types of stimuli would be rated on health. Health ratings (1: very unhealthy to 7: very healthy) were analyzed in a 2 (palatability: palatable vs. unpalatable) $\times 2$ (fat content: high-fat vs. lowfat $) \times 2$ (group: obese vs. control $) \times 2$ (manipulation: restaurant vs. health) ANOVA. The palatability factor is based on the pilot study. 
Unsurprisingly, low-fat foods ( $M=5.8, S D=0.4)$ were judged as healthier than high-fat foods $(M=3.1, S D=0.7)$, as was apparent from a main effect of fat content, $F(1,55)=908.98$, $p<0.001, \eta^{2}=0.94$. Moreover, unpalatable foods $(M=5.3, S D=0.5)$ were judged as healthier than palatable foods $(M=3.6, S D=0.5)$, as was apparent from a main effect of palatability, $F(1,55)=774.78, p<0.001, \eta^{2}=0.93$. Thus, when asked directly, participants considered low-fat foods as healthier than high-fat foods and unpalatable foods as healthier than palatable foods. ${ }^{2}$

\section{Analyses priming task ${ }^{3}$}

The reported analyses are for the dependent variables response latency (speed) and percentage of errors (accuracy). Response latencies associated with responses that were either too fast $(<200 \mathrm{~ms})$ or too slow $(>2000 \mathrm{~ms})$ were discarded, a total of only $0.35 \%$ of all trials. Response latencies associated with error responses $(5.1 \%)$ were also discarded. The assumption of equality of variances was checked per within-subjects contrast across the between-subjects groups with the Levene's Test of equality of error variances, and was not rejected. See Table 2 for all relevant statistics.

Fat content priming effect-response latencies. As can be seen in Fig. 1A, the manipulation had the expected effect. The pattern of latencies in the 'restaurant condition' suggests that health concerns did not play a role in participants' early associations on the affective priming task, in that the means suggest a preference for high-fat foods over low-fat foods. The pattern of latencies in the 'health condition' suggests that health aspects influenced responding in the priming task, in that the means suggest a preference for low-fat foods over high-fat foods. Consistent with our hypothesis, participants in the 'restaurant condition' displayed an opposite fat content priming effect as compared to participants in the 'health condition', as was apparent from the marginally significant target affect $\times$ prime fat content $\times$ manipulation interaction. Though the pattern of means is - as expected - in an opposite direction for each manipulation (see Fig. 1A), the target affect $\times$ prime fat content interaction was not significant in separate analyses for the 'restaurant condition' and the 'health condition'. The factor group did not influence the results.

Fat content priming effect-error percentages. In the analysis on error percentages, no evidence was found for any priming effects. See Fig. 1B for relevant means and standard errors.

Palatability priming effect - response latencies. In the analysis on response latencies, no evidence was found for any priming effects. See Fig. 2A for relevant means and standard errors.

\footnotetext{
${ }^{2}$ The effect of fat content was qualified by some interactions, which were deemed irrelevant for the current purposes of checking how the four types of primes would be rated on healthiness. For the lean control group, the effect of fat content was slightly stronger in the 'health' condition than in the 'restaurant' condition, as evidenced by a fat content $\times$ group $\times$ manipulation interaction, $F(1,55)=4.60, p<0.05, \quad \eta^{2}=0.08$, which qualified a fat content $\times$ manipulation interaction, $F(1,55)=3.60, p=0.06, \eta^{2}=0.06$, and a fat content $\times$ group interaction, $F(1,55)=4.74, p<0.05, \eta^{2}=0.08$. The effect of fat content tended to be slightly larger for palatable foods than for unpalatable foods, $F(1,55)=3.35, p=0.07, \eta^{2}=0.06$. Moreover, the effect of the factor palatability was a little stronger for the obese group than for the lean control group, $F(1,55)=5.69, p<0.05, \eta^{2}=0.09$.

${ }^{3}$ Analyses were also performed on the log-transformed latencies, by computing the natural logarithm of each mean RT per condition. This did not lead to different results or conclusions. Moreover, analyses were performed on the square-root transformed error percentages. Results of the overall error analyses were not affected. For the separate error analyses per manipulation ('restaurant' vs. 'health'), the $p$-value of the palatability priming effect in the restaurant condition went from $p=0.02$ to $p=0.07$, whereas the $p$-value of the palatability priming effect in the health condition went from $p=0.08$ to $p=0.13$.
} 
Table 2

Experiment 1

\begin{tabular}{|c|c|c|c|c|c|c|}
\hline & \multicolumn{3}{|c|}{ Response latencies } & \multicolumn{3}{|c|}{ Error percentages } \\
\hline & $F(1,55)$ & $p$ & $\eta^{2}$ & $F(1,55)$ & $p$ & $\eta^{2}$ \\
\hline \multicolumn{7}{|l|}{ Effects relevant for hypotheses } \\
\hline Target $\times$ prime-fat & 0.05 & 0.83 & 0.001 & 0.004 & 0.95 & $<0.001$ \\
\hline Target $\times$ prime-fat $\times$ group & 0.13 & 0.72 & 0.002 & 0.10 & 0.75 & 0.002 \\
\hline Target $\times$ prime-fat $\times$ manip & 3.74 & 0.06 & 0.06 & 0.43 & 0.51 & 0.01 \\
\hline Target $\times$ prime-fat WITHIN manip taste & 2.23 & 0.15 & 0.07 & & & \\
\hline Target $\times$ prime-fat WITHIN manip health & 1.54 & 0.23 & 0.05 & & & \\
\hline Target $\times$ prime-fat $\times$ group $\times$ manip & 0.17 & 0.68 & 0.003 & 0.47 & 0.50 & 0.01 \\
\hline Target $\times$ prime-pal & 0.85 & 0.36 & 0.02 & 0.14 & 0.71 & 0.003 \\
\hline Target $\times$ prime-pal $\times$ group & 0.44 & 0.51 & 0.01 & 0.37 & 0.54 & 0.01 \\
\hline Target $\times$ prime-pal $\times$ manip & 0.31 & 0.58 & 0.01 & 9.32 & 0.003 & 0.15 \\
\hline Target $\times$ prime-pal WITHIN taste manip & & & & 6.52 & 0.02 & 0.19 \\
\hline Target $\times$ prime-pal WITHIN health manip & & & & 3.24 & 0.08 & 0.11 \\
\hline Target $\times$ prime-pal $\times$ group $\times$ manip & 1.73 & 0.19 & 0.03 & 1.16 & 0.29 & 0.02 \\
\hline Target $\times$ prime-fat $\times$ prime-pal $(\times$ group $)(\times$ manip $)$ & $<1$ & $>0.54$ & $<0.01$ & $<1.42$ & $>0.24$ & $<0.03$ \\
\hline \multicolumn{7}{|l|}{ Effects irrelevant for hypotheses } \\
\hline Target & 19.14 & $<0.001$ & 0.26 & 4.66 & 0.04 & 0.08 \\
\hline Prime-fat $\times$ manip & 5.69 & 0.02 & 0.09 & & & \\
\hline Prime-fat $\times$ group $\times$ manip & & & & 2.82 & $<0.10$ & 0.05 \\
\hline Prime-pal & 3.12 & 0.08 & 0.05 & & & \\
\hline Prime-fat $\times$ prime-pal $\times$ group & & & & 3.22 & 0.08 & 0.06 \\
\hline$\times$ group $\times$ manip & & & & 7.10 & 0.01 & 0.11 \\
\hline
\end{tabular}

All effects that are relevant for our hypotheses are reported in this Table, and will be printed in bold when they are (marginally) significant. Significant, but for the hypothesis irrelevant, effects will also be reported. Irrelevant insignificant effects (all $p$-values $>.11$ ) will not be reported.

Note: target $=$ target affect, prime-pal $=$ prime palatability, prime-fat $=$ prime fat-content, manip $=$ manipulation .

Palatability priming effect-error percentages. The target affect $\times$ prime palatability $\times$ manipulation interaction was significant, which suggests that participants in the 'restaurant condition' displayed an opposite palatability priming effect as compared to the participants in the 'health condition'. Results for participants in the 'restaurant condition' suggest a liking of palatable foods over unpalatable foods, in that participants made fewer errors on congruent (palatable food prime - positive target or unpalatable food prime - negative target) trials than on incongruent (unpalatable food prime - positive target or palatable food prime - negative target) trials. Results for participants in the 'health condition' are indicative of a reversed priming effect, in that participants made fewer errors on incongruent trials than on congruent trials. This reversed palatability priming effect in the 'health' condition suggests that unpalatable foods are seen as more positive (healthier) than palatable foods. This finding is in accordance with the results of the health rating task as described before, in which indeed unpalatable foods were rated as healthier than palatable foods. In a separate analysis for the 'restaurant condition', the target affect $\times$ prime palatability interaction was significant, whereas this target affect $\times$ prime 


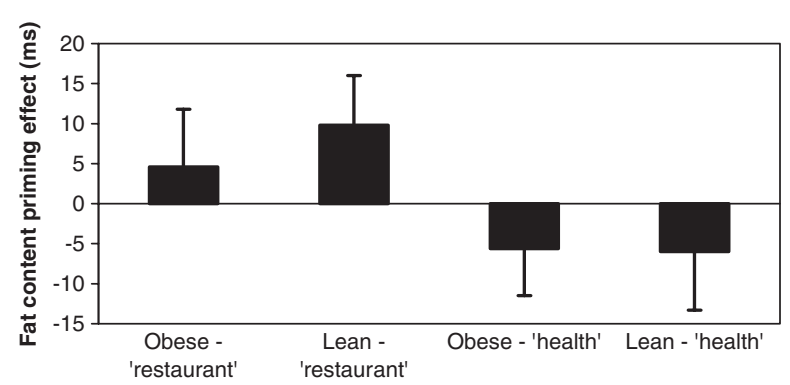

(A)

Participant group

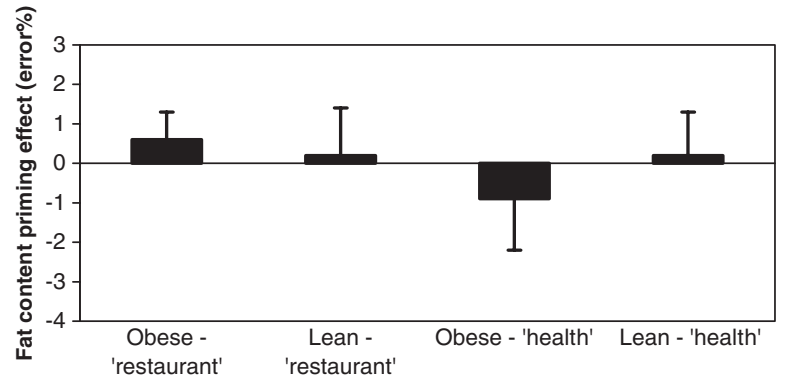

(B)

Participant group

Fig. 1. Experiment 1: The fat content priming effect as a function of participant group (obese vs. lean control) and manipulation (restaurant vs. health). The means are collapsed over the factor prime palatability. The fat content priming effect (RT and percentage of errors) for each participant is computed as: ((mean (high-fat-) + mean (low$f a t+)) / 2)-(($ mean $($ high-fat +$)+$ mean $(l o w-f a t-)) / 2)$. In this formula, 'high-fat' or 'low-fat' indicates the fat content of the prime, whereas the plus or minus sign right behind it, indicates whether the target was positive or negative. A positive score indicates a preference for high-fat foods over low-fat foods, and a negative score indicates a preference for low-fat foods over high-fat foods. Error bars represent one standard error. Panel A represents the results for the dependent variable response latencies, whereas Panel B represents the results for the dependent variable error percentages.

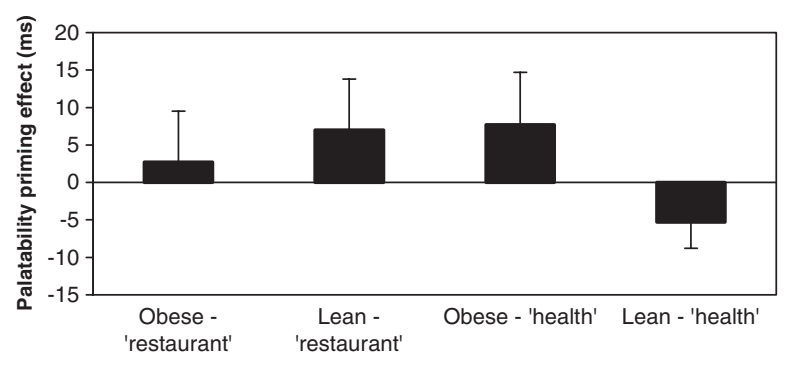

(A)

Participant group

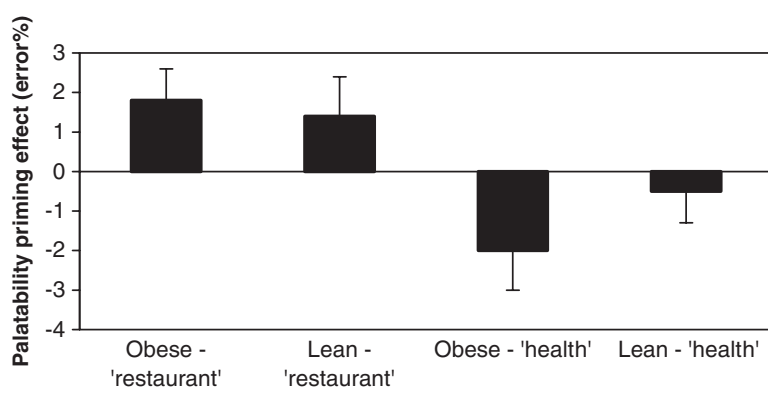

(B)

Participant group

Fig. 2. Experiment 1: The palatability priming effect as a function of participant group (obese vs. lean control) and manipulation (restaurant vs. health). The means are collapsed over the factor prime fat content. The palatability priming effect (RT and percentage of errors) for each participant is computed as: ((mean (palatable-) + mean $($ unpalatable +$)) / 2)-(($ mean $($ palatable +$)+$ mean $($ unpalatable -$)) / 2)$. In this formula, 'palatable' or 'unpalatable' indicates the palatability of the prime, whereas the plus or minus sign right behind it, indicates whether the target was positive or negative. A positive score indicates a preference for palatable foods over unpalatable foods, and a negative score indicates a preference for unpalatable foods over palatable foods. Error bars represent one standard error. Panel A represents the results for the dependent variable response latencies, whereas Panel B represents the results for the dependent variable error percentages.

palatability interaction was marginally significant, in a separate analysis for the 'health condition'. See Fig. 2B for relevant means and standard errors. The factor group did not influence the palatability priming effect. 


\section{In sum}

Results of the affective priming task suggest that the manipulation (restaurant task vs. health task) significantly influenced the direction of the priming effect, whereas no differences were found for the two groups (obese vs. lean control). So, a temporary change of attention focus prior to completing the affective priming task was effective in influencing the priming results. In the 'restaurant condition', taste appeared to be the basis for categorization of food, in that affective priming results suggest a liking of palatable foods over unpalatable foods. Results also suggest a more positive evaluation of high-fat foods than of low-fat foods as compared to the 'health condition'. In the 'health' condition, health appeared to be the basis for categorization of food. In this condition, results suggest a preference for unpalatable foods over palatable foods. This negative evaluation of palatable foods is in perfect accordance with the results of the health rating task in which palatable foods were indeed rated as unhealthier. Moreover, priming results also suggest a relative preference for low-fat foods over high-fat foods as compared to the 'restaurant condition'. Concluding, the results of Experiment 1 suggest that a temporary change in attention focus effectively influenced the priming effect, whereas weight status did not influence the direction or magnitude of the priming effect.

\section{Experiment 2}

In Experiment 1 we manipulated attention focus directly on a cognitive level. In Experiment 2 we are interested in the effects of a different manipulation - the induction of craving for food - on the priming effect. As described in the general introduction, a prior affective priming study with obese people in our laboratory found a more negative association with high-fat palatable foods than with low-fat palatable foods (Roefs, Stapert, et al., 2005). This finding might be explained by the health emphasizing context in which that study took place, a hospital. The current Experiment 2 took place in that same hospital, but prior to the affective priming task, participants were exposed to high-fat palatable foods (e.g., chocolate) to induce a state of craving for food. We expected this manipulation to have the effect of making the taste of food-instead of the healthiness of food - a salient characteristic, and thus the basis of categorization. Therefore we expected a positive palatability priming effect, in other words a liking for palatable foods over unpalatable foods on a relatively automatic level. Though in Experiment 1 we did not find evidence for the hypothesis that obese participants would show a more positive palatability priming effect than lean controls, we again tested the effect of weight-status on the palatability priming effect in Experiment 2. Moreover, like in Experiment 1, the primes were also differentiated in fat content, to test whether effects would be specific for either high-fat or lowfat foods.

\section{Method}

\section{Participants}

Participants were 27 obese women $($ BMI > 30) and 29 female lean unrestrained eaters. Restraint-status was again determined by the Restraint Scale, and a participant qualified as an unrestrained eater when she scored 14 or below. Obese participants were women who applied for 
Table 3

Experiment 2

\begin{tabular}{lllllr}
\hline & Obese $(n=27)$ & Control $(n=29)$ & $t$ & df & $p$ \\
\hline Age & $36.4(9.9)$ & $35.8(10.0)$ & 0.23 & 54 & 0.82 \\
BMI & $38.7(5.8)$ & $22.1(1.5)$ & & & \\
& $\left(R^{\mathrm{a}}: 31.0-56.7\right)$ & $(R: 18.8-24.5)$ & 14.6 & $29.3^{\mathrm{b}}$ & $<0.001$ \\
Restraint scale & $19.1(4.0)$ & $8.8(3.2)$ & 10.7 & 54 & $<0.001$ \\
Time of testing & $12.9(2.3)$ & $12.8(2.2)$ & 0.15 & 54 & 0.89 \\
Craving pretest & $24.8(24.6)$ & $44.1(28.1)$ & 2.73 & 54 & $<0.01$ \\
Initial craving $^{\mathrm{c}}$ & $61.9(21.2)$ & $77.8(14.5)$ & 3.25 & $45.5^{\mathrm{b}}$ & $<0.05$ \\
Craving task onset $^{\mathrm{d}}$ & $82.3(7.2)$ & $81.7(8.8)$ & 0.25 & 54 & 0.81 \\
Craving average $^{\mathrm{e}}$ & $83.0(6.0)$ & $83.5(6.8)$ & 0.33 & 54 & 0.74 \\
\hline
\end{tabular}

Participant characteristics, with $S D$ in parentheses.

${ }^{\mathrm{a}} R=$ Range.

${ }^{\mathrm{b}}$ Equality of variances could not be assumed.

${ }^{\mathrm{c}}$ The craving score after the first $5 \mathrm{~min}$ of craving induction.

${ }^{\mathrm{d}}$ The craving score prior to starting the task, after possible 2-min extensions of the craving manipulation to achieve the minimum value of 70 .

${ }^{\mathrm{e}}$ The average of the three craving scores prior to the starting of each block, after possible 2-min extensions of the craving manipulation.

gastric surgery at a local hospital. Some were on a waiting list for this operation, while others had been refused for this operation for various reasons. The lean controls were recruited by advertisements in local newspapers, by putting up advertisements in the hospital, and by asking participants whether they knew people who were willing to participate as well. The two groups of participants were matched on age and on time of testing. All participants were paid $€ 10$ for their participation. See Table 3 for participant characteristics.

Several additional participants - not included in the groups described above-were tested, but were excluded from analyses based on beforehand defined exclusion criteria. Two obese participants were excluded because of medical problems with the thyroid gland, and two participants ( 1 obese and 1 lean control) were excluded because of a high percentage $(>M+3 S D)$ of errors or responses that were either too fast or too slow, on the affective priming task.

\section{The affective priming task}

The specifications for the affective priming task were largely the same as in Experiment 1, with two exceptions. First, the apparatus running the experimental software was a Dell Inspiron 5000e notebook computer with a Pentium III processor, connected to a Philips Brilliance 105 monitor. Second, each trial started with a warning tone $(200 \mathrm{~ms})$, followed by a fixation cross $(500 \mathrm{~ms})$.

\section{Materials}

Food craving induction. The goal of this craving induction was to induce and maintain a state of craving for food during the affective priming task. Prior to the affective priming task, the extent of craving was first assessed on a $100 \mathrm{~mm}$ visual analog scale (VAS). This measurement will be 
referred to as the craving pretest (see Table 2). Then, the experimenter explained that it was very important for the current study to induce a state of craving for food. Three bowls with different kinds of foods (chocolate, croissant, and potato chips) were placed in front of the participant. If the participant did not like one of these foods, the item was replaced by a different food. The participant was then asked to intensely smell the food, and to eat a little bit of the food she liked best. The experimenter demonstrated and modeled how to smell the foods, and joined the participant in the craving induction procedure (cf., Jansen, 1998). After a 5 min craving induction, the extent of craving was again assessed on a VAS (this score will be referred to as the initial craving score). If this craving score was at least 70, the participant was ready to start the affective priming task. The food was left near the computer monitor, and the experimenter remained in the room during the computer task. If craving was not at the minimum level of 70 , the craving induction was repeated for a 2-min period, after which craving was assessed again (maximum of three repetitions). Prior to blocks 2 and 3 of the priming task, the craving induction was repeated for $2 \mathrm{~min}$, and was assessed again on a VAS scale. If craving was not maintained at a level higher than 70 , the craving induction was repeated for a period of $2 \mathrm{~min}$, with a maximum of three repetitions.

\section{Procedure}

Participants had all been asked not to consume any food during the two hours just prior to their participation. Compliance was checked by self-report before the start of the experiment. All participants complied with these instructions. Participants were tested individually in a quiet room in a local hospital, in the presence of the experimenter. The procedure was largely identical to the procedure in Experiment 1. The exception of course being that-instead of the 'attention focus manipulations'- the craving induction procedure was included between the practice trials and the start of the actual priming task, and just prior to blocks 2 and 3. The participant was briefly questioned about her medical history, the Restraint Scale (Herman \& Polivy, 1980) was completed, and height and weight were measured at the end of the experiment.

\section{Design and analysis procedure}

Data were analyzed using a 2 (target affect: positive vs. negative) $\times 2$ (fat-content prime: highfat vs. low-fat) $\times 2$ (palatability of prime: palatable vs. unpalatable) $\times 2$ (group: obese vs. control) analysis of variance. Target affect, fat-content prime, and palatability of prime were within subjects-factors, whereas the factor group was obviously a between-subjects factor. Partial eta squared $\left(\eta^{2}\right)$ is reported as a measure of effect size for all analyses.

\section{Results and discussion}

\section{Results affective priming paradigm ${ }^{4}$}

The reported analyses are for the dependent variable response latency only, because analyses on error percentages did not yield significant relevant results (all $p$ values $>.117$ ). Response latencies

\footnotetext{
${ }^{4}$ Analyses were also performed on the log-transformed latencies, by computing the natural logarithm of each mean RT per condition. This did not lead to different results or conclusions for either the ANOVA or the correlational analyses.
} 
Table 4

Experiment 2

\begin{tabular}{lccc}
\hline & $F(1,54)$ & $p$ & $\eta^{2}$ \\
\hline Effects relevant for hypotheses & & & $<0.001$ \\
Target $\times$ prime-fat & 0.003 & 0.96 & 0.02 \\
Target $\times$ prime-fat $\times$ group & 1.11 & 0.30 & 0.02 \\
Target $\times$ prime-pal & 0.81 & 0.37 & 0.03 \\
Target $\times$ prime-pal $\times$ group & 1.62 & 0.21 & $\mathbf{0 . 0 7}$ \\
Target $\times$ prime-fat $\times$ prime-pal & $\mathbf{4 . 2 1}$ & $<\mathbf{0 . 0 5}$ & 0.01 \\
Target $\times$ prime-pal WITHIN HF & 0.57 & 0.46 & $\mathbf{0 . 0 6}$ \\
$\quad$ Target $\times$ prime-pal WITHIN LF & $\mathbf{3 . 2 0}$ & $\mathbf{0 . 0 8}$ & 0.001 \\
Target $\times$ prime-fat $\times$ prime-pal $\times$ group & 0.03 & 0.86 & 0.38 \\
Effects irrelevant for hypotheses & & & 0.08 \\
Target & 33.56 & $<0.001$ & 0.03 \\
Prime-fat & 4.81 & & \\
\hline
\end{tabular}

All effects that are relevant for our hypotheses are reported in this Table, and will be printed in bold when they are (marginally) significant. Significant, but for the hypothesis irrelevant, effects will also be reported. Irrelevant insignificant effects (all $p$-values $>.13$ ) will not be reported.

Note: target $=$ target affect, prime-pal $=$ prime palatability, prime-fat $=$ prime fat-content; $\mathrm{HF}=$ high-fat foods; $\mathrm{LF}=$ low-fat foods.

associated with responses that were either too fast $(<200 \mathrm{~ms})$ or too slow $(>2000 \mathrm{~ms})$ were discarded, a total of only $.56 \%$ of all trials. Response latencies associated with error responses $(3.5 \%)$ were also discarded. The assumption of equality of variances was checked per withinsubjects contrast across the between-subjects groups with the Levene's Test of equality of error variances, and was not rejected. See Table 4 for all statistics.

Contrary to hypothesis, the manipulation did not have the effect of a simple palatability priming effect (i.e., a liking of palatable foods over unpalatable foods), as was evident from the nonsignificant target $\times$ prime palatability interaction, nor was this effect different between the two groups as was evident from the nonsignificant target $\times$ prime palatability $\times$ group interaction. Unexpectedly, the palatability priming effect was more positive for low-fat foods than for high-fat foods, as was evident from the three-way target $\times$ prime palatability $\times$ prime fat content interaction (see Fig. 3), suggesting that health aspects played a role. In a separate analyses for the low-fat foods, the target $\times$ prime palatability interaction was marginally significant, whereas this interaction was absent for the high-fat foods.

\section{Correlational analysis palatability priming effect}

The goal of our craving induction procedure was to induce a similar degree of craving in all participants (VAS rating between 70 and 100). The degree of craving was assessed at several times: before the craving induction (craving pretest), after the first $5 \mathrm{~min}$ of the craving induction (initial craving), prior to starting the affective priming task - after possible 2 min extensions to achieve a minimum degree of craving of 70 (craving task onset), and before each next block of the priming task (with possible 2-min extensions). Moreover, the average degree of craving experienced during 


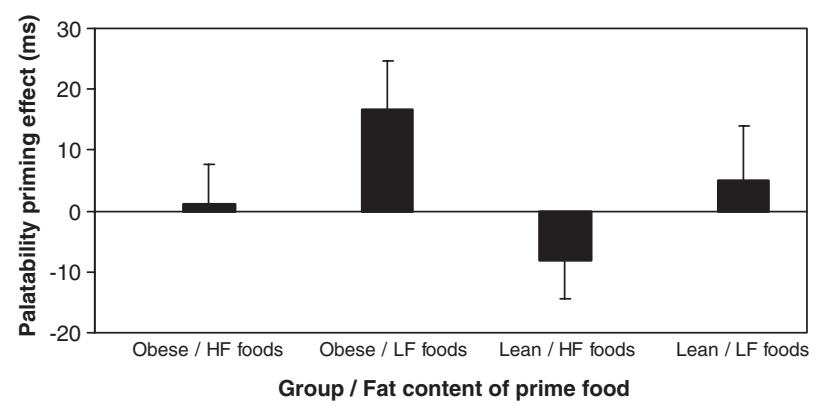

Fig. 3. Experiment 2: The palatability priming effect as a function of participant group (obese vs. lean control) and fat content of the food prime (high-fat vs. low-fat). The palatability priming effect for each participant is computed as: $(($ mean $($ palatable -$)+$ mean $($ unpalatable +$)) / 2)-(($ mean $($ palatable +$)+$ mean $($ unpalatable -$)) / 2)$. In this formula, 'palatable' or 'unpalatable' indicates the palatability of the prime, whereas the plus or minus sign right behind it, indicates whether the target was positive or negative. A positive score indicates a preference for palatable foods over unpalatable foods, and a negative score indicates a preference for unpalatable foods over palatable foods. Error bars represent one standard error.

the task was computed by averaging the craving scores before the start of each block (craving average). For all means, see Table 3.

VAS ratings suggest that the two groups of participants (obese vs. lean controls) indeed experienced similar degrees of craving at task onset, and on average during the task (see Table 2). Moreover, within each group, neither the craving score at task onset (obese: $r=0.07, p=0.74$; lean controls: $r=0.12, p=0.52$ ), nor the average craving score (obese: $r=0.19, p=0.34$; lean controls: $r=0.09, p=0.64$ ) correlated significantly with the palatability priming effect (calculated as the difference score between incongruent (palatable - negative/unpalatable - positive) and congruent (palatable - positive/unpalatable - negative) trials).

However, a possible correlation might have been obscured because of the restricted range (70-100). Moreover, these scores might have been influenced by socially desirable answering tendencies. The craving score at task onset and the average craving score reflect craving after (if needed) 2-min extensions of the craving induction, to achieve the required level of craving (70). The experimental demand can reasonably be expected to have played a larger role at later assessments of craving (after 2-min extensions) because participants knew that they were supposed to be in a state of craving, and might have indicated after repetitions that their craving was high just to be able to continue the task.

For these two reasons, we also looked at correlations between initial craving (i.e., the craving score after the first $5 \mathrm{~min}$ of the craving induction which could vary between 0 and 100) and the palatability priming effect. As can be seen in Table 3, lean controls scored higher on initial craving than obese participants. Moreover, this difference between groups was also apparent on the pretest. Interestingly, in the obese group, the palatability priming effect correlated significantly with initial craving, $r=0.49, p<0.01$, whereas it did not correlate with pretest craving, $r=0.06$, $p=0.78$. For the lean control group, the palatability priming effect was positively, but nonsignificantly, correlated with initial craving, $r=0.29, p=0.13$, and not correlated with pretest craving, $r=0.03, p=0.88$. Note that part of the variability in initial craving scores within each 
group might reflect sensitivity for craving, in that some participants may easier be brought in a state of craving. Another part of the variability in craving scores might reflect the degree to which participants fully immersed themselves in the craving induction.

Note that the group differences on the pretest and the initial craving scores may not reflect a true difference in craving, but may simply mean that the obese participants felt more inhibited to admit their craving on the VAS scale in comparison to the lean controls. To prevent a possible Type I error (falsely concluding a larger priming effect for the obese group than the lean controls, which was the effect of entering initial craving as a covariate), we decided not to include any of these variables as a covariate, but instead to report correlations separately for each group.

\section{In sum}

Interestingly, correlational analyses suggest that the palatability priming effect was related to initial craving for the obese group, in that the palatability priming effect was more positive with higher initial craving scores. This effect was in the same direction for the lean controls, but was not significant.

As was evident from the ANOVA, the craving manipulation did not simply lead to a palatability priming effect - a liking for palatable foods over unpalatable foods on a relatively automatic level-for all participants. Unexpectedly, the palatability priming effect was more positive for low-fat foods than for high-fat foods. This suggests that health aspects still might have played a role, possibly due to the hospital environment. The craving induction did not achieve its goal of focusing all participants on the palatability aspects of food in general, but just for the lowfat foods.

\section{General discussion}

\section{The malleability of attitudes toward food}

Relatively automatic evaluations of food certainly seem malleable by shifts in focus of attention. Weight-status on the other hand did not have an effect in either Experiment 1 or 2. This fits with our previous findings (Roefs, Stapert, et al., 2005) in which no difference in the food priming effect was found between obese people and normal weight controls either. Though not finding differences between obese people and normal weight controls are null-findings, it does seem that other factors - like focus of attention - are more important for the food priming effect.

In Experiment 1, the focus of attention was manipulated by a short task that either focused on the palatability of food or on the health aspects of food. This manipulation had the expected effect on the priming effect. When attention was focused on the palatability of foods, relatively automatic associations with food were indeed based on palatability, in that participants displayed a preference for palatable foods over unpalatable foods, and compared to the health condition a greater preference for high-fat foods than for low-fat foods. When attention was focused on health, relatively automatic associations with food were indeed based on health, in that participants displayed a preference for unpalatable (healthier) foods over palatable foods, and compared to the restaurant condition a greater preference for low-fat foods than for high-fat foods. The findings of Experiment 1 are comparable to findings of a recent study about attitudes 
toward smoking, in which attention was either focused on the sensory aspects of smoking or on the negative aspects of smoking such as health concerns and costs (Sherman, Rose, Koch, Presson, \& Chassin, 2003). In that study, participants displayed a positive priming effect for the picture stimuli that were related to the sensory aspects of smoking, whereas they displayed a negative priming effect for the picture stimuli that were related to the negative aspects of smoking.

In Experiment 2, for obese people the palatability priming effect became more positive with higher levels of experienced initial craving. For lean controls, the effect was in the same direction but missed significance. Unexpectedly, the craving induction did not achieve its goal of producing an overall palatability priming effect. Instead, the palatability priming effect was more positive for low-fat than for high-fat foods, suggesting that health concerns still might have played a role. This might be explained by the health-emphasizing environment, a hospital. So, the manipulation used in Experiment 2 was not strong enough to fully influence the priming effect, whereas the manipulation used in Experiment 1 influenced the priming effect more effectively. This might be because the affective priming task is cognitive in nature, and the manipulation used in Experiment 1 was too, whereas the manipulation used in Experiment 2 was not. The manipulation in Experiment 2 may have induced craving, but may not have succeeded in ruling out all healthbased associations.

In a prior study in our laboratory, we compared high and low restrained eaters on food (dis)likes in the same APP and in a related paradigm (Roefs, Herman, et al., 2005). Both of these studies were conducted in a relatively neutral environment (university), and all participants, independent of restraint status, preferred palatable foods over unpalatable foods. So, restrained and unrestrained eaters seemed to like foods to the same extent. Though restrained and unrestrained eaters did not differ in their relatively automatic evaluations of food, we hypothesized that they might differ in their craving for these foods ('wanting'; see e.g., Gendall \& Joyce, 2001; Klajner, Herman, Polivy, \& Chhabra, 1981; Legoff \& Spigelman, 1987). In other words, they may like foods to the same extent, but may independently differ in their 'wanting' of those foods (Berridge, 1996). So, the APP is then assumed to measure a relative liking, not a relative wanting of food.

Results of the current Experiment 2 suggest that the mechanism might be a little more complicated. Though the manipulation did not work for all participants, and did not lead to a general palatability priming effect, the manipulation did have some effect for obese people. When obese people experience higher levels of initial craving ('wanting'), they seem to prefer palatable foods over unpalatable foods to an increasingly greater extent, suggesting that palatability is a highly relevant characteristic of food then. In other words, increasing levels of craving may make the palatability related aspects of food increasingly salient, and thus the basis of categorization. It might be hypothesized that the same is true for normal-weight restrained eaters. These restrained eaters may not be in a permanently heightened state of craving. However, when experiencing a higher level of craving, they may have an increasingly strong preference for palatable foods over unpalatable foods. Relatedly, Lozano, Crites, and Aikman (1999) found that people rated foods more positively when in a state of hunger. Lozano et al. suggest that a state of hunger may increase the salience of the palatability aspects of food, and reduce the salience of health-related beliefs.

In the previous two paragraphs we compared research with restrained eaters to research with obese people. Note that in the current two experiments, BMI and restraint-status are confounded: 
the obese group scores on average higher on restraint than the normal-weight control group. It could be that unrestrained obese people would have responded differently in the current experiments. However, BMI and the engagement in weight-control behaviors are reported to be correlated (Neumark-Sztainer et al., 2000), which makes it difficult to find unrestrained obese people. Note also that the obese participants of the current Experiment 2 applied for gastric surgery, which might have made low restraint especially unlikely (for a similar line of reasoning see: Chua, Touyz, \& Hill, 2004). One should realize that this might constitute a specific group of obese people: they are very obese, and are about to undergo a heavy surgical procedure.

\section{The relation of food attitudes with eating behavior}

So, when people are in a certain situation in which the palatability of food is a very salient characteristic, they might forget about the health aspects of food, and not categorize foods in terms of health. This could encourage selecting and eating foods solely based on taste. Interestingly, Mann and Ward (2004) found that restrained eaters ate more when the food itself was made salient than when diet was made salient, when under high cognitive load. This high cognitive load caused participants to narrow their attention to only those salient cues ('diet' vs. 'appetizing').

In real life, situations and focus of attention can change relatively quickly; positive associations with palatable foods may quickly be overridden by more health-based negative associations. Imagine for example that you are walking through a street lined with nice restaurants, filled with the smell of good food. This would possibly make you think of the palatability of food. However, when you walk a little further, you may encounter a fitness gym, or a big advertisement for beach wear, which brings your focus back on the healthiness of food.

Recent studies and theorizing about obesity emphasize the role of the so-called 'toxic environment' in which we live (Hill \& Peters, 1998; Wadden, Brownell, \& Foster, 2002). "Our genes have not changed substantially during the past two decades. The culprit is an environment which promotes behaviors that cause obesity" (Hill \& Peters, 1998, p. 1371). On the other hand, beauty and being slim is considered very important in our society in which obesity is stigmatized (Puhl \& Brownell, 2003; Teachman \& Brownell, 2001). Obese people do realize that, as they more frequently report weight-control behaviors (Neumark-Sztainer et al., 2000). However, the palatability of food may be too salient in the environment, and the health aspects might be emphasized too little. Concluding, our toxic environment with many reminders of palatable foods, combined with studies suggesting that obese people and restrained eaters may be more impulsive (Chalmers, Bowyer, \& Olenick, 1990; Nederkoorn, Braet, Van Eijs, \& Jansen, 2004; Nederkoorn, Van Eijs, \& Jansen, 2004) might contribute to an explanation of the sudden rise in obesity.

\section{Acknowledgments}

This study was financed by the Netherlands Research Organization (NWO) Grant 425-20-801, awarded to Anita Jansen. The authors would like to thank Anne Vanempten en Kim Knipschild for testing the participants of Experiment 1. 


\section{Appendix}

High-fat palatable foods: chocola (chocolate), chips (chips), friet (fries), croissant (croissant), pizza (pizza), roomijs (ice cream).

High-fat unpalatable foods: haring (herring), speklap (slice of bacon), pate (pate), boter (butter), pindakaas (peanutbutter), walnoten (walnuts).

Low-fat palatable foods: aardbeien (strawberries), druiven (grapes), meloen (melon), kip (chicken), popcorn (popcorn), drop (liquorice).

Low-fat unpalatable foods: spruiten (Brussels sprouts), witlof (chicory), zuurkool (sauerkraut), andijvie (endive), radijs (radish), kabeljauw (cod).

Positive targets: vrede (peace), trouw (loyalty), zomer (summer), knuffel (hug), romantiek (romance), zonneschijn (sunshine), humor (humour), lente (spring), geschenk (gift), verrassing (surprise), cadeau (gift), baby (baby), feest (party), schoonheid (beauty), geboorte (birth), bruid (bride), bloesem (blossom), verjaardag (birthday), regenboog (rainbow), vlinder (butterfly), wens (wish), hemel (heaven), boeket (bouquet), melodie (melody).

Negative targets: oorlog (war), haat (hatred), ongeluk (accident), drugs (drugs), werkloosheid (unemployment), ongeval (accident), pijn (pain), dood (dead), scheiding (divorce), puist (pimple), zorgen (worries), roddel (gossip), belediging (insult), verdriet (grief), afval (garbage), schade (damage), angst (fear), schuld (guilt), vrees (fear), examens (exams), gebrek (defect), paniek (panic), vuilnis (garbage), mug (mosquito).

\section{References}

Banaji, M. R. (2001). Implicit attitudes can be measured. In H. L. Roediger III, J. S. Nairne, I. Neath, \& A. Surprenant (Eds.), The nature of remembering: Essays in honor of Robert G. Crowder (pp. 117-150). Washington, DC: APA.

Bargh, J. A. (1999). The cognitive monster. The case against the controllability of automatic stereotype effects. In S. Chaiken, \& Y. Trope (Eds.), Dual process theories in social psychology (pp. 361-382). New York, NY: Guilford Press.

Bargh, J. A., Chaiken, S., Govender, R., \& Pratto, F. (1992). The generality of the automatic attitude activation effect. Journal of Personality and Social Psychology, 62(6), 893-912.

Beringer, J. (1996). Experimental run time system (ERTS) [Computer software]. Frankfurt, Germany: Berisoft.

Berridge, K. C. (1996). Food reward: Brain substrates of wanting and liking. Neuroscience and Biobehavioral Reviews, $20,1-25$.

Blair, I. V. (2002). The malleability of automatic stereotypes and prejudice. Personality and Social Psychology Review, 6 , $242-261$.

Chalmers, D. K., Bowyer, C. A., \& Olenick, N. L. (1990). Problem drinking and obesity: A comparison in personality patterns and life-style. The International Journal of the Addictions, 25, 803-817.

Chua, J. L., Touyz, S., \& Hill, A. J. (2004). Negative mood-induced overeating in obese binge eaters: An experimental study. International Journal of Obesity, 28, 606-610.

De Houwer, J. (2001). A structural and process analysis of the Implicit Association Test. Journal of Experimental Social Psychology, 37, 443-451.

De Houwer, J. (2003). A structural analysis of indirect measures of attitudes. In J. Musch, \& K. C. Klauer (Eds.), The psychology of evaluation: Affective processes in cognition and emotion (pp. 219-244). Mahway, NJ: Erlbaum.

de Jong, P. J., Pasman, W., Kindt, M., \& van den Hout, M. A. (2001). A reaction time paradigm to assess (implicit) complaint-specific dysfunctional beliefs. Behaviour Research and Therapy, 39, 101-113. 
Drewnowski, A., Kurth, C., Holden Wiltse, J., \& Saari, J. (1992). Food preferences in human obesity: Carbohydrates versus fats. Appetite, 18, 207-221.

Eertmans, A., Baeyens, F., \& Van den Bergh, O. (2001). Food likes and their relative importance in human eating behavior: Review and preliminary suggestions for health promotion. Health Education Research, 16, 443-456.

Fazio, R. H., Jackson, J. R., Dunton, B. C., \& Williams, C. J. (1995). Variability in automatic activation as an unobstrusive measure of racial attitudes: A bona fide pipeline? Journal of Personality and Social Psychology, 69, 1013-1027.

Fazio, R. H., \& Olson, J. M. (2003). Implicit measures in social cognition research: Their meaning and use. Annual Review Psychology, 54, 297-327.

Fazio, R. H., Sanbonmatsu, D. M., Powell, M. C., \& Kardes, F. R. (1986). On the automatic activation of attitudes. Journal of Personality and Social Psychology, 50, 229-238.

Fazio, R. H., \& Towles-Schwen, T. (1999). The MODE model of attitude-behavior processes. In S. Chaiken, \& Y. Trope (Eds.), Dual-process theories in social psychology (pp. 97-116). NY/London: The Guilford Press.

Gendall, K. A., \& Joyce, P. R. (2001). Characteristics of food cravers who binge eat. In M. M. Hetherington (Ed.), Food cravings and addiction (pp. 567-583). London: Leatherhead Publishing.

Gerding, A. L., \& Weinstein, L. (1992). Taste ratings of obese people, and taste preferences based on geographical location. Bulletin of the Psychonomic Society, 30, 509-510.

Greenwald, A. G., McGhee, D. E., \& Schwartz, J. L. K. (1998). Measuring individual differences in implicit cognition: The implicit association test. Journal of Personality and Social Psychology, 74, 1464-1480.

Herman, C. P., \& Polivy, J. (1980). Restrained eating. In A. J. Stunkard (Ed.), Obesity (pp. 208-225). Philadephia: Saunders.

Hermans, D., \& De Houwer, J. (1994). Affective and subjective familiarity ratings of 740 Dutch words. Psychologica Belgica, 34, 115-139.

Hermans, D., De Houwer, J., \& Eelen, P. (1994). The affective priming effect: Automatic activation of evaluative information in memory. Cognition and Emotion, 8, 515-533.

Hermans, D., De Houwer, J., \& Eelen, P. (2001). A time course analysis of the affective priming effect. Cognition and Emotion, 15, 143-165.

Hill, A. J., \& Heaton-Brown, L. (1994). The experience of food craving: A propspective investigation in healthy women. Journal of Psychosomatic Research, 38, 801-814.

Hill, J. O., \& Peters, J. C. (1998). Environmental contributions to the obesity epidemic. Science, 280, 1371-1374.

Jansen, A. (1998). A learning model of binge eating: Cue reactivity and cue exposure. Behaviour Research and Therapy, $36,257-272$.

Klajner, F., Herman, C. P., Polivy, J., \& Chhabra, R. (1981). Human obesity, dieting, and anticipatory salivation to food. Physiology \& Behavior, 27, 195-198.

Lamote, S., Hermans, D., Baeyens, F., \& Eelen, P. (2004). An exploration of affective priming as an indirect measure of food attitudes. Appetite, 42, 279-286.

LeGoff, D. B., \& Spigelman, M. N. (1987). Salivary response to olfactory food stimuli as a function of dietary restraint and body weight. Appetite, 8, 29-35.

Lissner, L., \& Heitmann, B. (1995). Review: Dietary fat and obesity: Evidence from epidemiology. European Journal of Clinical Nutrition, 49, 79-90.

Lowery, B. S., Hardin, C. D., \& Sinclair, S. (2001). Social influence effects on automatic racial prejudice. Journal of Personality and Social Psychology, 81, 842-855.

Lozano, D. I., Crites, S. L., \& Aikman, S. N. (1999). Changes in food attitudes as a function of hunger. Appetite, 32, 207-218.

MacLeod, C. M. (1989). Directed forgetting affects both direct and indirect tests of memory. Journal of Experimental Psychology: Learning, Memory, and Cognition, 15, 13-21.

Mann, T., \& Ward, A. (2004). To eat or not to eat: Implications of the attentional myopia model for restrained eaters. Journal of Abnormal Psychology, 113, 90-98.

Mitchell, J. P., Nosek, B. A., \& Banaji, M. R. (2003). Contextual variations in implicit evaluation. Journal of Experimental Psychology: General, 132, 455-469. 
Nederkoorn, C., Braet, C., Van Eijs, Y., \& Jansen, A. (2004). Why obese children can not resist food: Impulsivity as a risk factor for obesity and an obstacle for treatment Unpublished manuscript.

Nederkoorn, C., Van Eijs, Y., \& Jansen, A. (2004). Restrained eaters act on impulse. Personality and Individual Differences, 37, 1651-1658.

Neumark-Sztainer, D., Rock, C. L., Thornquist, M. D., Cheskin, L. J., Neuhouser, M. L., \& Barnett, M. J. (2000). Weight-control behaviors among adults and adolescents: Associations with dietary intake. Preventive Medicine, 30, 381-391.

Nevo Tabel, Nederlands voedingsstoffenbestand (NEVO). (1993). Den Haag, The Netherlands [Dutch Food Composition Table].

Pliner, P., Herman, C. P., \& Polivy, J. (1990). Palatability as a determinant of eating: Finickiness as a function of taste, hunger, and the prospect of good food. In E. D. Capaldi, \& T. L. Powley (Eds.), Taste, experience, and feeding (pp. 210-225). Washington, DC: American Psychological Association.

Puhl, R., \& Brownell, K. D. (2003). Ways of coping with obesity stigma: Review and conceptual analysis. Eating Behaviors, 4, 53-78.

Rissanen, A., Hakala, P., Lissner, L., Mattlar, C. E., Koskenvuo, M., \& Ronnemaa, T. (2002). Acquired preference especially for dietary fat and obesity: A study of weight-discordant monozygotic twin pairs. International Journal of Obesity, 26, 973-977.

Roefs, A., Herman, C. P., MacLeod, C. M., Smulders, F. T. Y., \& Jansen, A. (2005). At first sight: How do restrained eaters evaluate high-fat palatable foods? Appetite, 44, 103-114.

Roefs, A., \& Jansen, A. (2002). Implicit and explicit attitudes towards high-fat foods in obesity. Journal of Abnormal Psychology, 111, 517-521.

Roefs, A., Stapert, D., Isabella, L. A. S., Wolters, G., Wojciechowski, F., \& Jansen, A. (2005). Early associations with food in anorexia nervosa patients and obese people assessed in the affective priming paradigm. Eating Behaviors, 6 , $151-163$.

Schwarz, N. (1999). Self-reports: How the questions shape the answers. American Psychologist, 54, 93-105.

Sherman, S. J., Rose, J. S., Koch, K., Presson, C. C., \& Chassin, L. (2003). Implicit and explicit attitudes toward cigarette smoking: The effects of context and motivation. Journal of Social and Clinical Psychology, 22, 13-39.

Smith, E. R., Fazio, R. H., \& Cejka, M. A. (1996). Accessible attitudes influence categorization of multiply categorizable objects. Journal of Personality and Social Psychology, 71, 888-898.

Teachman, B. A., \& Brownell, K. D. (2001). Implicit anti-fat bias among health professionals: Is anyone immune? International Journal of Obesity, 25, 1525-1531.

Teachman, B. A., Gregg, A. P., \& Woody, S. R. (2001). Implicit associations for fear-relevant stimuli among individuals with snake and spider fears. Journal of Abnormal Psychology, 110, 226-235.

Wadden, T. A., Brownell, K. D., \& Foster, G. (2002). Obesity: Responding to the global epidemic. Journal of Consulting and Clinical Psychology, 70, 510-525.

Weingarten, H. P., \& Elston, D. (1991). Food cravings in a college population. Appetite, 17, 167-175.

Zack, M., Toneatto, T., \& Macleod, C. M. (1999). Implicit activation of alcohol concepts by negative affective cues distinguishes between problem drinkers with high and low psychiatric distress. Journal of Abnormal Psychology, 108, $518-531$. 